\title{
An upcoming program for medical humanities education in Fudan University's School of Basic Medical Sciences
}

\author{
Ye Liu, Xunjia Cheng* \\ School of Basic Medical Sciences, Fudan University, Shanghai, China.
}

\begin{abstract}
Summary Ideal medical care requires professional skills as well as appropriate communication skills. However, traditional medical education in medical schools mostly emphasizes the former. To remedy this situation, medical humanities education will be incorporated into education for medical students at Fudan University. Comprehensive medical education that includes both medical skills and humanities may greatly improve medical care.
\end{abstract}

Keywords: Medical humanities, medical education, China

An author has opined that if we wish to have a truly humanistic ethic, we need a truly humanistic medicine first (1). It will be foreseen that the socio-humanistic approach on a medicine or biological perspective population health science fields will be absolutely necessary for the development of socio-humanistic competences. Humanities faculty, like faculty in undergraduate programs, were expected to focus in teaching and collegial activities at both local and national levels, and promotion were a function of excellence in medicine areas. However, the health-illness process is primarily a social and cultural process where the biological and the psychological are subsumed, and the health-illness process is socially and culturally determined (2,3). A program in Humane Medicine has been established in the School of Basic Medical Sciences at Fudan University, and presumably this program will be filled with clinicians with a particular interest in the humane aspects of medicine. Under the new program, the School of Basic Medical Sciences hopes to educate medical students who can reform China's healthcare system and thus increase the public's wellbeing. The program was long anticipated but it was delayed because of a certain level of ignorance regarding developments

Released online in J-STAGE as advance publication April 29, 2017.

*Address correspondence to:

Dr. Xunjia Cheng, School of Basic Medical Sciences, Fudan University, No.131 Dong'an Rd, Xujiahui District, Shanghai 200032, China.

E-mail: xjcheng@shmu.edu.cn in medical humanities and scientific conventions. A key aspect of this program is a focus on the potential contributions of medical humanities in clinical practice. Humanities should be clearly connected to medical practice and medical research so that medical students and clinicians comprehend the human aspects of their work. An optimal mixture of professional competencies is needed to teach medical humanities, including personnel with a combination of medical and humanities training and personnel specializing solely in the humanities.

In the Humane Medicine program, learning activities will be designed to meet medical knowledge, skills, and attitudinal objectives. Traditionally, clinical knowledge was taught a lecture-based or problem- or case-based approach, and uncompleted humane medicine knowledge were acquired during in the clinical years. The Humane Medicine program has facilitated an earlier or more extensive approach to learning. Another priority has been introducing medical students to humane medicine activity or course development early in their course. The trend away from the traditional medical student's curriculum approach to humane medicine course learning in medicine has forced to develop innovative strategies in junior medical student's education system.

Implementation of the program must be accelerated to realize the potential of humane medicine. This is especially important because humanistic skills can be learned. Medical schools might consider integrating courses that teach humanistic qualities into their full curriculum and student evaluations like those used at other universities or institutions (4-6). The Humane 
Medicine program will provide an essential avenue for lifelong learning by medical doctors and clinicians. It aims to integrate humanistic qualities of individual components of critical appraisal by simulating a reallife event. Healthcare personnel need to focus on and improve their communication with patients and their families; basically, they need to learn how to unite the humanistic aspects of care with its technical aspects; how to be professionals without losing their humanistic identity. The Humane Medicine program also allows students to practice giving and receiving peer review, an opportunity that was not previously available to them.

Students have been sent a very clear message regarding the need for a specific program in humane medicine, and this program is driven by assessment. The program's results and impact will be evaluated by an independent evaluation system. Student progress within the program will be assessed using written examinations, and students will be rated on their ability to apply their knowledge of the basic sciences and skills that underpin clinical medicine to the practice of medicine at an appropriate level. Presumably, a practical examination in medical humanities would be a more accurate test of whether students have the clinical communication skills they need to succeed at the next level of their medical training.

\section{References}

1. Epstein M. For a truly humanistic ethic, we need truly humanistic medicine. BMJ. 2014; 348:g1133.

2. Loh KY, Sivalingam N. Enhancing doctor-patient relationship: The humanistic approach. Med J Malaysia. 2008; 63:85-87.

3. Quintero GA. Medical education and the healthcare system - Why does the curriculum need to be reformed? BMC Med. 2014; 12:213.

4. Markides M. The importance of good communication between patient and health professionals. J Pediatr Hematol Oncol. 2011; 33:S123-125.

5. Martimianakis MA, Michalec B, Lam J, Cartmill C, Taylor JS, Hafferty FW. Humanism, the hidden curriculum, and educational reform: A scoping review and thematic analysis. Acad Med. 2015; 90:S5-S13.

6. Ahlzén R, Stolt CM. The humanistic medicine program at the Karolinska Institute, Stockholm, Sweden. Acad Med. 2003; 78:1039-1042.

(Received April 2, 2017; Revised April 17, 2017; Accepted April 19, 2017) 